\title{
Phytothermotherapy in osteoarthritis: new evidence for an old therapy
}

\author{
This article was published in the following Dove Press journal: \\ Botanics: Targets and Therapy \\ 13 November 2013 \\ Number of times this article has been viewed
}

\section{Sara Cheleschi \\ Sara Tenti \\ Mauro Galeazzi \\ Antonella Fioravanti}

Rheumatology Unit, Department of Medicine, Surgery, and Neuroscience, University of Siena, Siena, Italy
Correspondence: Antonella Fioravanti Rheumatology Unit, University of Siena, Policlinico "Le Scotte", Viale Bracci I, 53 100 Siena, Italy

Tel +390577233345

Fax +39057740450

Email fioravanti7@virgilio.it
Introduction: Osteoarthritis (OA) is the most common disabling joint disease worldwide Moreover, its incidence and prevalence are increasing because of aging, higher life expectancy, and lifestyle changes, leading to a growing population of patients with OA. Current treatment of OA includes nonpharmacologic and pharmacologic modalities. Phytothermotherapy (PTT) is a singular crenotherapic treatment consisting of immersing oneself in pools of fermenting alpine grass, to exploit its heat and rich, aromatic components. The efficacy of PTT in OA is bolstered by ancient tradition. However, there is a marked lack of clinical validation of its efficacy and tolerability in current literature. The aim of this review was to evaluate the currently available knowledge of possible clinical effects and mechanisms of action of PTT in OA.

Methodology: We searched PubMed and Scopus (the period examined was 1980-2012) for clinical trials examining the effect of PTT in OA. MEDLINE was searched using the term "phytothermotherapy" and "hay baths" in combination with "osteoarthritis." We included only papers published in English or Italian and in peer-reviewed journals.

Results: We identified three trials describing the results of PTT in OA. The available data demonstrate that PTT is efficacious in decreasing pain and disability and improving function in patients with OA. Moreover, the tolerability of PTT is excellent. The mechanisms of action of PTT are not yet completely known, although it is probably due to different combined mechanical, physical, and chemical effects.

Discussion: PTT could represent a useful aid in the treatment of OA or a valid alternative for patients who do not tolerate pharmacologic treatments. However, further studies on a larger number of patients are needed to provide more precise therapeutic guidelines on the modalities of use of PTT. Additionally, there is a need for other botanical investigations and research on the mechanisms of action of PTT.

Keywords: phytothermotherapy, osteoarthritis, fresh grass, fermenting grass

\section{Introduction}

Osteoarthritis (OA) is the most common disabling joint disease worldwide. Moreover, its incidence and prevalence are increasing because of aging, higher life expectancy, and lifestyle changes, leading to a growing population of patients with OA. ${ }^{1,2}$ Structural damage of the articular cartilage constitutes a hallmark of OA, resulting from an increased imbalance of cartilage degradation and synthesis. ${ }^{3}$ Current treatment of OA includes nonpharmacologic and pharmacologic modalities. ${ }^{4,5}$ Nonpharmacologic therapies include exercise, manual therapy, weight reduction, instructions in joint protection techniques, provision of assistive devices and insoles, thermal therapy, and use of joint splints. ${ }^{4,5}$ Pharmacologic therapy has been largely confined to analgesics, nonsteroidal anti-inflammatory drugs (NSAIDs), or selective cyclooxygenase-2 
(COX 2) inhibitors (COXibs). However, the use of NSAIDs is associated with well-known gastrointestinal and (less frequently) renal side effects ${ }^{6,7}$ and is limited by their negative side effects on cartilage metabolism. ${ }^{8-10}$ On the other hand, the use of COXibs is characterized by an increase in cardiovascular side effects. ${ }^{11,12}$ Acetaminophen is better tolerated compared with NSAIDs and COXibs but does not always provide adequate pain relief. ${ }^{13,14}$ These reasons often lead to the use of other, complementary or alternative therapies. ${ }^{15}$

Phytothermotherapy (PTT) is a singular crenotherapeutic treatment consisting of immersing oneself in pools of fermenting alpine grass, to exploit its heat and rich, aromatic components. The traditional expression "hay baths," corresponding to the German "heybaeder," is actually inappropriate, because in reality for PTT only fresh grass or frozen grass to avoid desiccation is used. The traditional name, although substantially incorrect, undoubtedly derives from the fact that this procedure was originally linked to haymaking practices. The expressions "grass baths" or more simply "phytothermotherapy" thus seem more accurate. ${ }^{16}$ Bathing in fermenting mountain grass for alleviation of "joint pain" is a rather ancient practice traditionally carried out in some areas of northeast Italy and Austria. Various sources report that even at the beginning of the 19th century, peasants from some areas of those regions spent a whole day in haymaking, and then during the evening used to lie down on a bed of freshly cut grass. They woke up in the morning feeling perfectly refreshed and in great shape. ${ }^{17}$ Throughout the second half of the 19th century, this popular practice gradually begun to assume the features of an accepted medical practice. In 1871, Dr Lersh ${ }^{18}$ from Aachen, Germany, in one of his writings on PTT, observed that "grass baths" were used not only by peasants but also by all people suffering from "joint pain." Actually, PTT is studied and used for treating many rheumatic diseases (RDs), especially in the area of Monte Bondone, a mountain above Trento (Italy).

The main indications for this method include OA and other degenerative joint diseases, extra-articular rheumatisms, both generalized, such as fibromyalgia syndrome, and localized forms. ${ }^{16,19}$ The efficacy of PTT in OA is bolstered by ancient tradition. However, despite its long history and popularity, there is a marked lack of clinical validation of its efficacy and tolerability in current literature. In an era of evidence-based medicine, it is necessary to ask what real medical and scientific value this therapy has. The aim of this review is to evaluate the currently available information on possible clinical effects and mechanisms of action of PTT in OA. We also provide some suggestions for further development in this area.

\section{The method of phytothermotherapy}

The herbs used for PTT come from mountain meadows that are situated at altitudes between 1,200 and 1,500 m. This particular altitude represents a strategy because not only does it guarantee a peculiar floral mix but also it avoids insects and other parasites, which are practically nonexistent over 1,200 meters above sea level. The grass is a special composite blend of different herbs, encompassing woundwort, Arnica montana (European arnica, mountain tobacco, leopard's bane), Achillea millefolium (yarrow), Alchemilla vulgaris (bear's foot, ladies mantle), Plantago media (plantain), Thymus serpyllum (thyme), Taraxacum alpinum (blow ball, lion's tooth), Vaccinium myrtillus (blueberry), and Gentiana lutea (gentian). ${ }^{20}$

The grass is mowed, collected, and transported down to the valley and is then placed in $50 \mathrm{~cm}$ thick vats, where, left to ferment, it develops heat due to its own metabolic activity as well as that of the associated microbial flora. After 1-2 days, the deeper layers reach temperatures of $60^{\circ} \mathrm{C}$ or more, which are maintained throughout the whole thermal treatment.

The patient immerses him or herself in the warm bath and is covered with a 10-20 cm thick layer of grass every day for 20 minutes. After each bath, the patient lies on a reaction couch, wrapped in a woolen blanket, for 30-45 minutes. The reaction is characterized by profuse sweating, which gradually diminishes in 3-4 hours. A complete cycle of PTT lasts 10 days, with a 1-day interval halfway through the cure. Such a break is necessary to prevent a possible reaction called "thermal crisis," characterized by asthenia, migraines, insomnia, malaise, and increased joint pain, which can manifest after the third or fourth bath. ${ }^{16,21}$

This particular method described is also used today to treat many RDs such as OA.

\section{Methodology}

We conducted a search of the literature in January 2013. We searched PubMed and Scopus (the period examined was 1980-2012) for clinical trials examining the effect of PTT in OA.

MEDLINE was searched using the term "phytothermotherapy" and "hay baths" in combination with "osteoarthritis." We included only papers published in English or 
Italian and in peer-reviewed journals. Diagnosis of OA met American College of Rheumatology criteria. ${ }^{22,23}$

\section{Results}

\section{Clinical studies in OA}

We identified three trials describing the results of PTT in OA (Table 1). To verify the efficacy of PTT in OA, Miori et $\mathrm{al}^{16}$ performed an open study on 27 patients (15 of them with a generalized OA form). The following clinical features were considered: pain in affected joints evaluated by Visual Ana$\log$ Scale (VAS), presence of global subjective improvement (or lack of it) at the end of the therapy and 6 months after treatment, degree of global functional impairment, morning stiffness duration, and handgrip strength. The mean score at the affected joints (on the VAS) was $2.51 \pm 0.71$ before and $1.83 \pm 0.89$ after treatment $(P<0.001)$, with improvement in $68 \%$ of patients. Morning stiffness was reduced from $38.9 \pm 30.5$ to $17.5 \pm 17.2$ minutes $(P<0.05)$, with improvement in $57 \%$ of patients. Grip strength measure went from $136 \pm 59.7 \mathrm{mmHg}$ to $147 \pm 51 \mathrm{mmHg}(P<0.01)$, with improvement in $77 \%$ of patients. Patient general assessment demonstrated an improvement in $72 \%$ of cases immediately after treatment and in $80 \%$ after 6 months. Tolerability was high in 23 out of 27 patients. Nobody was taken off treatment because of side effects, although in two cases a 1-day interval due to asthenia was introduced.

In another observational study, Miori et $\mathrm{al}^{24}$ reported the long-term efficacy of one cycle of PTT in a group of patients affected by gonarthrosis, in comparison with the outcome of a conventional medical treatment and physiokinesitherapy (FKT). A total of 142 patients with primary knee OA were included in the study: 54 patients (group 1) were treated with a single course of PTT, 58 patients (group 2) continued with their usual outpatient care, and 30 patients (group 3) were treated with a course of FKT. For each group of consecutively treated patients, the authors evaluated the Lequesne algofunctional index, ${ }^{25}$ a validated, disease-specific questionnaire addressing in a single index knee pain (five questions scored on a $0-2$ scale, with 0 indicating absent and 2 indicating severe), function limitation (four questions, same scale), and maximum distance walked (one question scored on a 0-6 distance scale, with 0 indicating ability to walk unlimited distances and 6 indicating ability to walk $<100$ meters); the worst possible total score is 24 points. The drug consumption and the frequency of the patient-physician contact after 10-15 days of treatment and at 3, 6, 9, and 12 months with blind telephonic follow-up were also investigated. In each group, the Lequesne algofunctional score diminished at the end of the treatment and remained lower than at basal time in group 1 and group 2, but not in group 3, at 3, 6, 9, and 12 months. This study underlines the mild long-term (follow-up 6 months) efficacy of grass baths on both pain and functionality in knee OA. These data were recently confirmed by Fioravanti et $\mathrm{al}^{26}$ in a single-blind, controlled randomized trial in patients with primary symptomatic OA of the knee, hip, and lumbar spine. Two hundred and eighteen outpatients of both sexes (83 males, 135 females) affected by primary knee or hip OA who met the American College of Rheumatology criteria ${ }^{22,23}$ and patients with lumbar spine OA defined at X-ray by disc space narrowing and at least one level of osteophyte or osteosclerosis ${ }^{27}$ were included in the study. All patients had been symptomatic (VAS $>30 \mathrm{~mm}$ ) for at least 3 months prior to inclusion in the study. Patients were randomly allocated into two groups: group 1 (109 patients) were submitted to PTT at the thermal center of Garniga Terme (Trento, Italy) and group 2 (109 patients) as a control group

Table I Clinical trials of PTT in OA

\begin{tabular}{|c|c|c|c|c|c|c|c|}
\hline Author & $\begin{array}{l}\text { OA } \\
\text { localization }\end{array}$ & $\begin{array}{l}\text { Trial } \\
\text { design }\end{array}$ & $\begin{array}{l}\text { Sample } \\
\text { size }\end{array}$ & Intervention & $\begin{array}{l}\text { Main } \\
\text { outcomes }\end{array}$ & Follow-up & Results \\
\hline $\begin{array}{l}\text { Miori } \\
\text { et } \text { al }^{16}\end{array}$ & $\begin{array}{l}\text { I } 5 \text { patients with } \\
\text { generalized OA }\end{array}$ & Open study & 27 & Group I: PTT & $\begin{array}{l}\text { VAS, morning stiffness, } \\
\text { grip strength, patient } \\
\text { general assessment }\end{array}$ & 24 weeks & $\begin{array}{l}\text { General improvement of } \\
\text { all parameters persisting } \\
\text { after } 24 \text { weeks }\end{array}$ \\
\hline $\begin{array}{l}\text { Miori } \\
\text { et } \mathrm{al}^{24}\end{array}$ & Knee OA & $\begin{array}{l}\text { Observational } \\
\text { study }\end{array}$ & 142 & $\begin{array}{l}\text { Group I: PTT } \\
\text { Group 2: } \\
\text { outpatient care } \\
\text { Group 3: FKT }\end{array}$ & $\begin{array}{l}\text { Lequesne index, drug } \\
\text { consumption, frequency } \\
\text { of physician and clinical } \\
\text { examinations }\end{array}$ & 48 weeks & $\begin{array}{l}\text { Persisting improvement } \\
\text { of Lequesne Index after } \\
8 \text { weeks in groups I and } 2\end{array}$ \\
\hline $\begin{array}{l}\text { Fioravanti } \\
\text { et } \mathrm{al}^{26}\end{array}$ & $\begin{array}{l}\text { Knee, hip, and } \\
\text { lumbar OA }\end{array}$ & SB-RCT & 218 & $\begin{array}{l}\text { Group I: PTT } \\
\text { Group 2: } \\
\text { outpatient care }\end{array}$ & $\begin{array}{l}\text { VAS, HAQ, Lequesne } \\
\text { index, RMQ, drug } \\
\text { consumption }\end{array}$ & 12 weeks & $\begin{array}{l}\text { Persisting efficacy of PTT } \\
\text { in group I }\end{array}$ \\
\hline
\end{tabular}

Abbreviations: FKT, physiokinesitherapy; HAQ, Health Assessment Questionnaire; OA, osteoarthritis; PTT, phytothermotherapy; RMQ, Roland Morris Questionnaire; SB-RCT, single-blind randomized clinical trial; VAS, Visual Analog Scale. 
and continued regular outpatient care (exercises, NSAIDs, and/or analgesics). Group 1 patients were submitted to ten generalized daily immersions of 20 minutes each in warm $\left(50^{\circ} \mathrm{C}-58^{\circ} \mathrm{C}\right)$ hay baths. Patients in both groups were advised to note daily in a diary their consumption of analgesics and NSAIDs. Patients were assessed at baseline, after 2 weeks, and after 3 months from the beginning of the study and were evaluated by VAS for pain intensity, Health Assessment Questionnaire (HAQ), ${ }^{28}$ Lequesne index for hip and knee OA, ${ }^{25}$ Roland Morris Questionnaire for lumbar spine OA (an important tool to assess function of patients with low back pain), ${ }^{29}$ and symptomatic drug consumption. In patients treated with PTT, the authors observed a significant improvement of VAS at the end of the treatment and 3 months later, and in the HAQ index after 15 days. Furthermore, a significant reduction of NSAID consumption was reported in group 1. In the control group, no significant differences were noted, compared with the basal time. The analyses performed separately for each subgroup of OA localization showed that the best results were evident in lumbar spine OA patients. In particular, the Roland Morris Questionnaire decreased significantly $(P<0.001)$ after treatment and remained stable during the rest of the follow-up period, whereas in the control group there was not a significant modification of the RMQ score in any of the follow-up assessments. Concerning tolerability, in the group treated with PTT, $10 \%$ of patients presented side effects due to treatment, but these were of low intensity and did not interrupt the therapy. In conclusion, this study showed the beneficial carryover symptomatic effects of a cycle of PTT in patients with OA of the hip, knee, or lumbar spine.

\section{Tolerability}

Studies performed on the behavior of a series of physiological parameters $^{30,31}$ and careful monitoring for possible onset of side effects, mainly in patients presenting comorbidities and of advanced age, have demonstrated the excellent tolerability of PTT. Exclusion criteria are basically limited to those patients with nonstabilized ischemic cardiopathies, decompensated nephropathies, cardiopathies and hepatopathies, other serious internistic forms, neoplasms skin pathologies involving a continuous cutaneous lesion, acute inflammatory processes, or active phlebitis or phlebothrombosis. Patients presenting articular forms in a phase of evident phlogistic activity also need to be excluded, as well as patients with a known personal history of allergies, hay fever, pollen allergies, or food intolerances. ${ }^{30,31}$ Few cutaneous papules, usually nonitchy, frequently appear, resolving themselves spontaneously in a few days simply by continuing with the cure. Ten percent of patients may suffer a worsening of the joint pain symptomatology immediately after completing the entire baths cycle; however, this does not entail a reduction of the benefits seen during medium and long-term follow-up. The presence of arthroprosthesis of the lower extremities is not considered a contraindication.

\section{Mechanisms of action}

As for other thermal therapies, the actual mechanisms of action of PTT are not yet completely known, although they are probably ascribable to a series of different combined mechanical, physical, chemical, and physiochemical effects. ${ }^{32,33}$ Such mechanisms may be distinguished aspecifically as common to hot baths in general, and specifically as dependent upon the composition of the particular herbs used. ${ }^{20}$ It has been reported that hot stimuli produce analgesia on nerve endings by increasing the pain threshold. According to the "gate theory," pain relief may be due to the temperature and hydrostatic pressure of water on the skin. ${ }^{34}$ Moreover, thermal stimulation increases the extensibility of collagen-rich tissues, such as tendons, fasciae, and articular capsules, which may improve the range of joint motion. ${ }^{32}$ These effects of PTT on muscle tone, joint mobility, and pain intensity may be effective in all the RDs, especially in OA characterized by painful symptoms and prolonged muscle tension. The baths' high temperatures induce rapid superficial hyperemia together with an initial deep decongestion, followed by active hyperemia of the deep tissues, including periarticular tissues (capsules, ligaments). It has been demonstrated by measuring limb circumference, by bioimpedance analysis, and by measuring skin moisture that by the end of the PTT treatment there is a marked reduction in tissue imbibition. ${ }^{31}$ Furthermore, thermal stress provokes a series of neuroendocrine reactions. In particular, the heat stimulates the release of adrenocorticotropic hormone, cortisol, prolactin, and growth hormone, although it does not alter the circadian rhythm of these hormones. ${ }^{35}$ The effect of thermal stress on the hypothalamus-pituitary-adrenal axis seems to be particularly important for the antiedemigenous and anti-inflammatory actions of corticosteroids, as well as for the frequent alteration of the axis during some RDs. ${ }^{36}$ The increase in $\beta$-endorphin demonstrated to occur with various spa therapy techniques ${ }^{37-40}$ has an analgesic and antispastic effect that is particularly important in patients for whom pain is the prevalent symptom. This increase in $\beta$-endorphin is probably the key factor in the mechanism of individual tolerance to thermal baths. The effects described make it possible to break the vicious circle of pain-muscle 
contraction-altered joint dynamics pain that characterizes many chronic arthropathies.

Furthermore, recent studies have shown after various spa therapy techniques a reduction of circulating levels of prostaglandin $\mathrm{E}_{2}$ and leukotriene $\mathrm{B}_{4}$, which are important mediators of inflammation and pain, in patients suffering from OA. ${ }^{41,42}$

Moreover, in patients with OA, PTT induces an increase of blood levels of heat shock protein such as Hsp $70 .{ }^{43}$ In cell cultures of chondrocytes and in animal models of arthritis, Hsp70 has been shown to provide protection from cellular injuries and apoptosis. ${ }^{44}$ Specific effects of PTT may be due to the active ingredients (essential oils, terpenes, and other aromatic substances) contained in the fermenting grass, which, favored by vasodilatation, enter the body during the bath. ${ }^{45}$

Other specific factors may also contribute to the clinical improvement observed after PTT, including the change in environment, pleasant scenery/surroundings, the absence of work duties, physical and mental relaxation, the noncompetitive atmosphere with similarly suffering companions, and physical therapy. These spa benefits are especially important in studies evaluating the effects of PTT compared with no treatment or another treatment. $32,33,46,47$

\section{Discussion}

The aim of this review was to summarize the currently available information on clinical effects and mechanisms of action of PTT in OA. The results of clinical trials on PTT that we have described here suggest a positive effect in decreasing OA pain and improving articular functionality. The studies assessed the medium to long-term effect and found that the clinical efficacy of PTT lasted for 3-6 months. The persistent symptomatic effects of PTT in OA demonstrated in clinical studies are in line with those of other trials of spa therapy for various RDs performed previously ${ }^{27,48-53}$ and with our previous contribution on PTT in patients affected by fibromyalgia. ${ }^{54}$ Nguyen et $\mathrm{al}^{27}$ reported that spa therapy of 3 weeks' duration had a carryover of beneficial symptomatic effects ( 6 months) in patients with lumbar spine, knee, and hip OA. Guillemin et $\mathrm{al}^{49}$ concluded that the addition of spa therapy for patients with low back pain had a positive short-term and a moderate long-term (9 months) effectiveness on chronic low back pain. van Tubergen et $\mathrm{al}^{50}$ reported that in patients with ankylosing spondylitis, a 3-week course of combined spa and exercise therapy, in addition to drug treatment, provided beneficial effects for at least 40 weeks. In a previous study, ${ }^{54}$ we investigated the effects of PTT in patients affected by fibromyalgia, demonstrating pain relief and significant improvement of the fibromyalgia-related symptoms and quality of life during follow-up (12 and 24 weeks). Moreover, PTT seems to be well tolerated, with slight and transitory side effects.

On the other hand, it is important to underline that in literature there is a great lack of studies in the field of PTT and OA. Furthermore, some aspects of these studies are disputable and could be a source of bias. For example, comparisons of the studies were difficult. In these trials the baseline characteristics of the patients were heterogeneous, the methods used for assessment of efficacy varied, and the patients were assessed at different times after PTT (Table 1).

Only one of the studies reported is randomized and none has a double-blind design, because of the difficulty of creating a placebo with the same characteristics as the treatment. Because of the lack of double-blinded studies, the placebo effect cannot be excluded and may contribute to confound results.

Furthermore, the mechanisms of action of PTT are not fully understood, and one of the critical points is the controversial problem of the absorption of the active ingredients (essential oils, terpenes, and other aromatic substances) contained in the fermenting grass: ie, the demonstration of specific effects other than those linked to the simple action of heat. Unfortunately, few studies have been conducted on this topic, and little is known about the specific effects of various fermenting grasses. This lack of evidence is also linked to the ongoing controversy in the health care professions concerning the role of alternative medicine, which includes, among others, PTT. Some proponents of alternative medicine feel that its value has been established by traditional use and it should be integrated into medical education and practice, whereas others are skeptical about this field because of the lack of scientific medicine. Hoping to overcome these controversies, more botanical investigations and research on the mechanisms of action of PTT are not only necessary but even advisable. ${ }^{55}$

\section{Conclusion}

PTT could represent a useful aid in the treatment of some RDs such as OA. This therapy could also represent a good alternative for all those patients who cannot tolerate conventional pharmacologic treatments or are at risk of serious side effects.

The value of this therapeutic approach largely depends on the respect of some basic general rules, such as a correct diagnosis and characterization of the evolutionary phase of the disease, the accurate assessment of the patient's general health status to exclude potential contraindications, and a good knowledge of the therapeutic medium utilized, including its indications and possible side effects. 
Given the positive preliminary results of PTT in the treatment of patients with OA, further clinical investigations on larger populations and different RDs are highly recommended, in order to widen the indications of this treatment modality and reduce the impact of drug toxicity and side effects.

\section{Disclosure}

All authors declare no conflicts or competing financial interests in this work.

\section{References}

1. Zhang Y, Jordan JM. Epidemiology of osteoarthritis. Clin Geriatr Med. 2010;26(3):355-369.

2. Bijisma JW, Berenbaum F, Lafeber FP. Osteoarthritis: an update with relevance for clinical practice. Lancet. 2011;377(9783):2115-2126.

3. Pelletier JM. Pathophysiology of osteoarthritis. Osteoarthtritis Cartilage. 2004;12:S31-S33.

4. Jordan KM, Arden NK, Doherty M, et al. EULAR recommendations 2003: An evidence based approach to the management of knee osteoarthritis: report of a task force of the Standing Committee for International Clinical Studies Including Therapeutic Trials (ESCISIT). Ann Rheum Dis. 2003;62(12):1145-1155.

5. Hochberg MC, Altman RD, April KT, et al. American College of Rheumatology 2012 recommendations for the use of non pharmacologic and pharmacologic therapies in osteoarthritis of the hand, hip, and knee. Arthritis Care Res. 2012;64(4):465-474.

6. Ofman JJ, MacLean CH, Straus WL, et al. A meta-analysis of severe upper gastrointestinal complications of nonsteroidal anti-inflammatory drugs. J Rheumatol. 2002;29(4):804-812.

7. Brater DC. Anti-inflammatory agents and renal function. Semin Arthritis Rheum. 2002;32(3 Suppl 1):33-42.

8. Huskisson EC, Berry H, Gishen P, Jubb RW, Whitehead J. Effects of antiinflammatory drugs on the progression of osteoarthritis of the knee. LINK Study Group. Longitudinal investigation of nonsteroidal antiinflammatory drugs in knee osteoarthritis. J Rheumatol. 1995;22(10):1941-1946.

9. Brandt KD. Effects of nonsteroidal anti-inflammatory drugs on chondrocyte metabolism, in vitro and in vivo. Am J Med. 1987; 83(Suppl 5A):29-34

10. Ding C. Do NSAIDs affect the progression of osteoarthritis? Inflammation. 2002;26(3):139-142.

11. Bresalier RS, Sandler RS, Quan H, et al. Cardiovascular events associated with rofecoxib in a colorectal adenoma chemoprevention trial. N Engl J Med. 2005;352(11):1092-1102.

12. Kearney PM, Baigent C, Godwin J, Halls H, Emberson JR, Patrono C. Do selective cyclo-oxygenase-2 inhibitors and traditional non-steroidal anti-inflammatory drugs increase the risk of atherothrombosis? Meta-analysis of randomised trials. BMJ. 2006;332(7553):1302-1308.

13. Zhang W, Jones A, Doherty M. Does paracetamol (acetaminophen) reduce the pain of osteoarthritis?: a meta-analysis of randomised controlled trials. Ann Rheum Dis. 2004;63(8):901-907.

14. Pincus T, Wang X, Chung C, Sokka T, Koch GG. Patient preference in a crossover clinical trial of patients with osteoarthritis of the knee or hip: face validity of self-report questionnaire ratings. $J$ Rheumatol. 2005;32(3):533-539.

15. Zochling J, March L, Lapsley H, Cross M, Tribe K, Brooks P. Use of complementary medicines for osteoarthritis: a prospective study. Ann Rheum Dis. 2004;63(5):549-554.

16. Miori R, Contu C, Marzano A, Fedrizzi A, Bambara LM. Critical evaluation of phytothermotherapy ("hay baths") in degenerative arthropathies. Clin Ter. 1994;144(1):31-42.

17. Atzwanger H. Das voelser heubad. [The hay bath Voelser]. Der Schlern. 1936; 17:75-79
18. Lersh BM. Polymorphe Balneologie, eine Abhandlung über Sandbäder, Schlamm- und Moorbäder, Kiefernadelbäder und manche andere weniger gebräuchliche Arten von Bädern: Eine Abhandlung über Sandbäder, Schlamm- und Moorbäder, Kiefernadelbäder und manche andere weniger gebräuchliche Arten von Bädern. [Polymorphic Balneology, a treatise on sand baths, mud baths and mud baths, pine needle baths and some other less common types of baths: A Treatise on sand baths, mud baths and mud baths, pine needle baths and some other less common types of baths] Erlangen, Enke, 1871. German.

19. Tenti S, Manica P, Galeazzi M, Fioravanti A. Phytothermotherapy in fibromyalgia and osteoarthritis: between tradition and modern medicine. Europ J Int Med. 2013;5(3):248-253.

20. Talamucci P, Piemontese S, Coser P. Risultati preliminari sulle modalità di utilizzazione e di conservazione dell'erba dei pascoli del Monte Bondone a fini terapici ("bagni di fieno"). [Preliminary results on the procedures for the use and conservation of grass in the pastures of Monte Bondone purposes terapici ("hay baths")]. Report Centro di Ecologia Alpina. 1995;1:1-20.

21. Miori R, Manica P, Bambara LM. Phytothermotherapy with fermenting alpine grass: duration of therapeutic effect. Presented at: 34th Congress of the International Society of Medical Hydrology and Climatology. Budapest, Hungary. October 14-19, 2002.

22. Altman R, Asch E, Bloch D, et al. Development of criteria for the classification and reporting of osteoarthritis. Classification of osteoarthritis of the knee. Diagnostic and Therapeutic Criteria Committee of the American Rheumatism Association. Arthritis Rheum. 1986;29(8):1039-1049.

23. Altman R, Alarcón G, Appelrouth D, et al. The American College of Rheumatology criteria for the classification and reporting of osteoarthritis of the hip. Arthritis Rheum. 1991;34(5):505-514.

24. Miori R, Paolazzi G, Albertazzi R. Phytothermotherapy with fermenting alpine grass in knee osteoarthritis: mid-long term results. Reumatismo. 2008;60(4):282-289.

25. Lequesne MG, Mery C, Samson M, Gerard P. Indexes of severity for osteoarthritis of the hip and knee. Validation - value in comparison with other assessment tests. Scand J Rheumatol Suppl. 1987;65:85-89.

26. Fioravanti A, Bellisai B, Iacoponi F, Manica P, Galeazzi M. Phytothermotherapy in osteoarthritis: a randomized controller clinical trial. J Altern Complement Med. 2011;17(5):407-412.

27. Nguyen M, Revel M, Dougados M. Prolonged effects of 3 week therapy in a spa resort on lumbar spine, knee and hip osteoarthritis: followup after 6 months. A randomized controlled trial. Br J Rheumatol. 1997;36(1):77-81.

28. Ranza R, Marchesoni A, Calori G, et al. The Italian version of the Functional Disability Index of the Health Assessment Questionnaire. A reliable instrument for multicenter studies on rheumatoid arthritis. Clin Exp Rheumatol. 1993;11(2):123-128.

29. Roland M, Morris R. A study of the natural history of back pain. Part I. Development of a reliable and sensitive measure of disability in low-back pain. Spine. 1983;8(2):141-144.

30. Miori R, Manica P, Bortoli P, Carletto A, Bambara L. I bagni nell'erba (fitobalneroterapia, "bagni di fieno"). [The bathrooms in the grass (fitobalneroterapia, "hay baths"). Efficacy, tolerance and directions]. Efficacia, tolleranza e indicazioni. Clin Term. 2003;50:63-82.

31. Miori R, Manica P, Bortoli P, Caramaschi P, Bambara LM. Variazioni di alcuni parametri fisiologici dell'organismo nel corso dei bagni fitobalneoterapici (bagni nell'erba, bagni di fieno) in soggetti osteoartrosici. [Changes in some physiological parameters of the organism in the course of fitobalneoterapici bathrooms (baths in the grass, hay) in osteoarthritic subjects]. Clin Term. 2003;50:83-100.

32. Sukenik S, Flusser D, Abu-Shakra M. The role of SPA therapy in various rheumatic diseases. Rheum Dis Clin North Am. 1999;25(4):883-897.

33. Fioravanti A, Cantarini L, Guidelli GM, Galeazzi M. Mechanism of action of spa therapies in rheumatic diseases: what scientific evidence is there? Rheumatol Int. 2011;31(1):1-8.

34. Melzack R, Wall P. Pain mechanism: a new theory. Science. 1965; 150(3699):971-979. 
35. Kuczera M, Kokot F. The influence of SPA therapy on endocrine system. Stress reaction hormones. Pol Arch Med Wewn. 1996;95(1):11-20.

36. Gur A, Cevik R, Sarac AJ, Colpan L, Em S. Hypothalamic-pituitary-gonadal axis and cortisol in young women with primary fibromyalgia: the potential roles of depression, fatigue, and sleep disturbance in the occurrence of hypocortisolism. Ann Rheum Dis. 2004;63(11):1504-1506.

37. Laatikainen T, Salminen K, Kohvakka A, Pettersson J. Response of plasma endorphins, prolactin and catecholamines in women to intense heat in a sauna. Eur J Appl Physiol Occup Physiol. 1988;57(1):98-102.

38. Vescovi PP, Gerra G, Pioli G, Pedrazzoni M, Maninetti L, Passeri M. Circulating opioid peptides during thermal stress. Horm Metab Res. 1990;22(1):44-46.

39. Cozzi F, Lazzarin P, Todesco S, Cima L. Hypothalamic-pituitaryadrenal axis dysregulation in healthy subjects undergoing mud-bath applications. Arthritis Rheum. 1995;38(5):724-725.

40. Bellometti S, Galzigna L. Function of the hypothalamic adrenal axis in patients with fibromyalgia syndrome undergoing mud-pack treatment. Int J Clin Pharmacol Res. 1999;19(1):27-33.

41. Ardiç F, Ozgen M, Aybek H, Rota S, Cubukçu D, Gökgöz A. Effects of balneotherapy on serum IL-1, PGE2 and LTB4 levels in fibromyalgia patients. Rheumatol Int. 2007;27(5):441-446.

42. Bellometti S, Galzigna L. Serum levels of a prostaglandin and a leukotriene after thermal mud pack therapy. J Investig Med. 1998;46(4):140-145.

43. Verzelloni E, Russo F, Agostini G, Manica P, Conte A. Serum heat shock proteins in knee joint osteoarthritis patients treated with grass thermal therapy. Pharmacology Online. 2006;3:839-844.

44. Grossin L, Cournil-Henrionnet C, Pinzano A, et al. Gene transfer with Hsp70 in rat chondrocytes confers cytoprotection in vitro and during experimental osteoarthritis. FASEB J. 2006;20(1):65-75.

45. De Francesco F, Nicolini G, Chemini C, Girardi M. Simulator for chemical and physical study in the phyto-bathing-therapy. Presented at: 34th Congress of the International Society of Medical Hydrology and Climatology. Budapest, Hungary. October 14-19, 2002.
46. Bender T, Karagülle Z, Bálint GP, Gutenbrunner C, Bálint PV, Sukenik S. Hydrotherapy, balneotherapy, and spa treatment in pain management. Rheumatol Int. 2005;25(3):220-224.

47. Guidelli GM, Tenti S, De Nobili E, Fioravanti A. Fibromyalgia syndrome and spa therapy: myth or reality? Clin Med Insights Arthritis Musculoskelet Disord. 2012;5:19-26.

48. Forestier R, Desfour H, Tessier JM, et al. Spa therapy in the treatment of knee osteoarthritis: a large randomised multicentre trial. Ann Rheum Dis. 2010;69(4):660-665.

49. Guillemin F, Constant F, Collin JF, Boulange M. Short and longterm effect of spa therapy in chronic low back pain. Br J Rheumatol. 1994;33(2):148-151.

50. van Tubergen A, Landewé R, van der Heijde D, et al. Combined spaexercise therapy is effective in patients with ankylosing spondylitis: a randomized controlled trial. Arthritis Rheum. 2001;45(5):430-438.

51. Bálint GP, Buchanan WW, Adám A, et al. The effect of the thermal mineral water of Nagybaracska on patients with knee joint osteoarthritisa double blind study. Clin Rheumatol. 2007;26(6):890-894.

52. Evcik D, Kavancu V, Yeter A, Ygit I. The efficacy of balneotherapy and mud-pack therapy in patients with knee osteoarthritis. Joint Bone Spine. 2007;74(1):60-65.

53. Harzy T, Ghani N, Akasbi N, Bono W, Chakib N. Short- and long-term therapeutic effects of thermal mineral waters in knee osteoarthritis: a systematic review of randomized controlled trials. Clin Rheumatol. 2009;28(5):501-507.

54. Fioravanti A, Bellisai B, Capitani S, Manica P, Paolazzi G, Galeazzi M. Phytothermotherapy: a possibile complementary therapy for fibromyalgia patients. Clin Exp Rheumatol. 2009;27(56):S29-S32.

55. Marcus DM. Alternative medicine and the arthritis foundation. Arthritis Rheum. 2002;47(1):5-7.
Botanics: Targets and Therapy

\section{Publish your work in this journal}

Botanics: Targets and Therapy is an international, peer-reviewed, open access journal focusing on the discovery and development of active compounds based upon or found naturally occurring in the plant kingdom that may have therapeutic potential in any disease state. The manuscript management system is completely online and includes a very

Submit your manuscript here: http://www.dovepress.com/botanics-targets-and-therapy-journal

\section{Dovepress}

quick and fair peer-review system. Visit http://www.dovepress.com/ testimonials.php to read real quotes from published authors. 